\title{
In-vitro antimicrobial activity of four diallyl sulphides occurring naturally in garlic and Chinese leek oils
}

\author{
SHYH-MING TSAO and MEI-CHIN YIN* \\ Department of Internal Medicine, Chungshan Hospital, Taichung and *Institute of Nutritional Science, \\ Chungshan Medical and Dental College, Taichung, Taiwan, R.O.C.
}

\begin{abstract}
The in-vitro antimicrobial activity of garlic oil, Chinese leek oil and four diallyl sulphides occurring naturally in these oils against Staphylococcus aureus, methicillin-resistant $S$. aureus (MRSA), three Candida spp. and three Aspergillus spp. (total of 276 clinical isolates) was studied. The magnitude of activity of the four diallyl sulphides followed the order diallyl tetrasulphide $>$ diallyl trisulphide $>$ diallyl disulphide $>$ diallyl monosulphide. These results suggest that disulphide bonds are an important factor in determining the antimicrobial capabilities of these sulphides. The concentration of four diallyl sulphides in garlic and Chinese leek oils was in the range 41.7-52.7\% of total sulphides. Garlic oil, with a higher concentration of four diallyl sulphides, showed greater antimicrobial activity than Chinese leek oil. Diallyl disulphide, diallyl trisulphide, diallyl tetrasulphide and the oils rich in these sulphides may have a role in the prevention or treatment of infections.
\end{abstract}

\section{Introduction}

Methicillin-resistant Staphylococcus aureus (MRSA), Candida spp. and Aspergillus spp. are the most commonly identified bacterial and fungal species responsible for severe nosocomial infections in Taiwan [1-3]. Such infections not only require expensive antibiotic treatments but also increase morbidity and mortality in hospitalised patients. To control these infections, there is a need for other agents with greater antimicrobial activity and less toxicity. The antimicrobial activity and other medical benefits of garlic oil have been widely recognised [4-6]. These benefits have been attributed to the presence of sulphides in garlic oil $[5,6]$. Because they are easy to obtain or prepare as well as having good stability, the medical properties of the garlic constituents diallyl monosulphide and diallyl disulphide have been the focus of many studies [7-10]. A chemical analysis of garlic oil showed that $54.5 \%$ of the total sulphides comprised diallyl monosulphide, diallyl disulphide, diallyl trisulphide and diallyl tetrasulphide [11]. Although diallyl trisulphide and diallyl tetrasulphide accounted for $26.6 \%$ of the total sulphides in garlic oil, little attention has been paid to the medical benefits of these two

Received 27 April 2000; revised version accepted 29 Dec. 2000.

Corresponding author: Dr M-C. Yin (e-mail mcyin@ mercury.csmc.edu.tw). components. The inhibitory effect of diallyl disulphide, but not diallyl monosulphide, against $C$. albicans has been reported previously [12]; however, information regarding the activity of these two agents against Aspergillus spp. and MRSA is limited. The antimicrobial activity of garlic extract against $S$. aureus has been observed [13]; however, whether garlic oil can inhibit MRSA and fungal pathogens remains unknown. Also, the compounds in garlic oil responsible for any inhibitory effect require further elucidation.

Like garlic, Chinese leek is a member of the Allium family and a vegetable commonly used in oriental society. Apart from garlic and onion, little attention has been paid to the potential medical benefits of Allium plants. Recently, the antioxidant and antifungal activities of aqueous extracts from Chinese leek and other Allium plants were studied in this laboratory $[14,15]$. The present study extended these observations by examining the antimicrobial activities of four diallyl sulphides occurring naturally in garlic and Chinese leek oils with a view to the development of new antibiotic agents or new functional foods.

\section{Materials and methods}

\section{Sample preparation}

Garlic bulbs (Allium sativum L.) and Chinese leeks ( $A$. odorum L.) were purchased directly from farms. The 
method of Ravid and Putievsky [16] was used to prepare essential oil. Fresh plant materials were steamdistilled for $3 \mathrm{~h}$ in a 100-L direct steam pilot plant apparatus. The oil recovered $(2.2 \sim 4.3 \mathrm{~g}$ of oil $/ \mathrm{kg}$ of garlic bulb; $1.1 \sim 3.5 \mathrm{~g}$ of oil $/ \mathrm{kg}$ of Chinese leek) was stored at $-80^{\circ} \mathrm{C}$ until used.

\section{Standard preparation}

Diallyl monosulphide (purity 97\%) and crude diallyl disulphide (purity 80\%) were purchased from Aldrich Chemical Co. (Milwaukee, WI, USA). Diallyl disulphide was further purified by fractional distillation and its final purity was $>98 \%$ when examined by highperformance liquid chromatography (HPLC). Diallyl trisulphide and diallyl tetrasulphide were obtained by fractional distillation from crude diallyl disulphide. The identification of diallyl trisulphide and diallyl tetrasulphide was confirmed by ${ }^{1} \mathrm{H}-\mathrm{NMR}$ spectroscopy $\left(\mathrm{CDC1}_{3}, 300 \mathrm{MHz}\right)$ as described by Sparnins et al. [17]. Standards were stored at $-80^{\circ} \mathrm{C}$ until used.

\section{Analysis of four diallyl sulphides in garlic and Chinese leek oil}

One mg of essential oil prepared from each plant was redissolved in $10 \mathrm{ml}$ of acetonitrile immediately before compositional analysis by the method of Lawson et al. [11]. A 2- $\mu 1$ sample was injected into a Hitachi C18 HPLC with a Supelco LC-18, $250 \mathrm{~mm} \times 4.6 \mathrm{~mm}$ $\times 5 \mu \mathrm{m}$ column and acetonitrile:water:tetrahydrofuran (70:27:3) at a flow rate of $1 \mathrm{ml} / \mathrm{min}$ as eluent, and the absorbance of fractions was read at $240 \mathrm{~nm}$. Standards were used to identify and quantify these diallyl sulphides in oils prepared from garlic and Chinese leek.

\section{Strains and medium}

S. aureus, MRSA, three Candida spp. (C. albicans, $C$. krusei, C. glabrata) and three Aspergillus spp. ( $A$. niger, A. flavus, A. fumigatus) were isolated from infected patients in Chungshan Hospital (Taichung, Taiwan). The total numbers of clinical isolates of $S$. aureus, MRSA and fungi were 40, 60 and 176, respectively. All isolates were identified by conventional methods [18] and routinely maintained on nutrient agar or Sabouraud dextrose agar (Difco, Detroit, MI, USA) at $25^{\circ} \mathrm{C}$ until used.

\section{Antibacterial tests}

Diallyl monosulphide, diallyl disulphide, diallyl trisulphide, diallyl tetrasulphide standards and the two essential oils were tested against $S$. aureus and MRSA. Methicillin, penicillin, cefotaxime and tetracycline were purchased from Sigma and used as comparitors. Microdilution MICs were determined with strains grown in cation-adjusted Mueller-Hinton broth according to National Committee for Clinical Laboratory Standards (NCCLS) guidelines [19]. The concentra- tions of agents were $128-0.125 \mathrm{mg} / \mathrm{L}$. All incubations were at $35^{\circ} \mathrm{C}$. Clavulanic acid at a concentration of $2 \mathrm{mg} / \mathrm{L}$ in the medium was used to verify the production of $\beta$-lactamase in these clinical isolates.

\section{Antifungal tests}

The four diallyl sulphides and two essential oils were diluted 10-fold in polyethylene glycol because of their poor solubility. All agents were further diluted 1 in 5 in RPMI 1640 medium. A broth macro-dilution method was performed as described by the NCCLS [20] with agent concentrations of $128-0.125 \mathrm{mg} / \mathrm{L}$. Agent-free and fungi-free controls were included. Turbidity was measured spectrophotometrically at $530 \mathrm{~nm}$ after incubation for $48 \mathrm{~h}$ at $35^{\circ} \mathrm{C}$ in RPMI 1640 medium containing $0.165 \mathrm{M}$ morpholinepropanesulphonic acid (MOPS) ( $\mathrm{pH}$ 7.0). The MIC was defined as the concentration that produced $80 \%$ reduction in turbidity, compared with that of agent-free controls. Amphotericin B (Sigma) was used for comparison in antifungal tests. Isolates were classified as susceptible if the MIC was $\leqslant 8 \mathrm{mg} / \mathrm{L}$ resistant if the MIC was $>64 \mathrm{mg} / \mathrm{L}$.

\section{Statistical analysis}

MICs were expressed as the mean and SD of five experiments. Data were treated by analysis of variance (ANOVA) which was calculated with SAS [21]. Differences between means were determined by the least significance difference test with significance defined at $\mathrm{p} \leqslant 0.05$.

\section{Results}

The concentrations of diallyl monosulphide, diallyl disulphide, diallyl trisulphide and diallyl tetrasulphide in garlic and Chinese leek oils is presented in Table 1. The concentrations of the four diallyl sulphides in garlic oil were higher than in Chinese leek oil $(p<0.05)$. The MIC values of four antibiotics, garlic oil, Chinese leek oil and the four diallyl sulphides against the $40 \mathrm{~S}$.

Table 1. Content* of four diallyl sulphides in garlic oils and Chinese leek oils

\begin{tabular}{|c|c|c|}
\hline \multirow[b]{2}{*}{ Sulphides } & \multicolumn{2}{|c|}{ Concentration $(\mu \mathrm{g} / \mathrm{g})$ in } \\
\hline & Garlic oils & Chinese leek oils \\
\hline DAS & $112(7)$ & $104(11)$ \\
\hline DADS & $1183(42)$ & $943(45)$ \\
\hline DAT & $751(24)$ & 494 (37) \\
\hline DATS & 368 (19) & $341(21)$ \\
\hline Sum $^{\dagger}$ & $2414(227)$ & $1882(187)$ \\
\hline Total sulphides & $4581(383)$ & $4508(432)$ \\
\hline *Percent of sulphides & 52.7 & 41.7 \\
\hline
\end{tabular}

Data are expressed as mean (SD) $(n=5)$.

DAS, diallyl monosulphide; DADS, diallyl disulphide; DAT, diallyl trisulphide; DATS, diallyl tetrasulphide.

${ }^{*}$ Limit of detection is $5 \mu \mathrm{g} / \mathrm{g}$.

${ }^{\dagger} \mathrm{Sum}=\mathrm{DAS}+\mathrm{DADS}+\mathrm{DAT}+\mathrm{DATS}$.

$\$ \%=$ sum of four diallyl sulphides $\times 100 /$ total sulphides. 
aureus and 60 MRSA isolates are presented in Table 2. All agents tested inhibited the growth of non-MRSA $S$. aureus with the four antibiotics showing greater activity than the two essential oils and four diallyl sulphides. However, the antibiotic MIC values against MRSA were $>64 \mathrm{mg} / \mathrm{L}$; diallyl disulphide, diallyl trisulphide and diallyl tetrasulphide showing greater inhibitory effects than these antibiotics. The MIC values for the two essential oils and four diallyl sulphides against six fungal pathogens are presented in Table 3. The MIC values of amphotericin B against the 176 clinical fungal isolates were in the range $0.25-4 \mathrm{mg} / \mathrm{L}$ (data not shown), indicating no resistance. The two essential oils, diallyl monosulphide and diallyl disulphide showed poorer antifungal activities than amphotericin B; however; diallyl trisulphide and diallyl tetrasulphide showed similar inhibitory effects.

\section{Discussion}

Garlic has been reported to have inhibitory activity against $S$. aureus [13]. The results of the present study extend the known antimicrobial activity of garlic oil to MRSA and six medically important fungi. Furthermore, the essential oil prepared from another member of the Allium family, Chinese leek, also possessed similar antimicrobial capabilities. The MIC values of garlic and Chinese leek oils against MRSA and six fungal pathogens were $<64 \mathrm{mg} / \mathrm{L}$ (Tables 2 and Table 3);

Table 2. MIC of four antibiotics, garlic oil, Chinese leek oil and four diallyl sulphides against 40 wild-type S. aureus and $60 \mathrm{MRSA}$

\begin{tabular}{lcc}
\hline & \multicolumn{2}{c}{ MIC (mg/L) against } \\
\cline { 2 - 3 } Agents & S. aureus & MRSA \\
\hline Methicillin & $0.5(0.25)$ & $>64.0$ \\
Penicillin & $0.5(0.125)$ & $>64.0$ \\
Cefotaxime & $1.0(0.25)$ & $>64.0$ \\
Tetracycline & $1.0(0.25)$ & $>64.0$ \\
Garlic oil & $24.0(4.0)$ & $32.0(8.0)$ \\
Chinese leek oil & $36.0(6.0)$ & $48.0(8.0)$ \\
Diallyl monosulphide & $20.0(4.0)$ & $32.0(8.0)$ \\
Diallyl disulphide & $4.0(1.0)$ & $12.0(2.0)$ \\
Diallyl trisulphide & $2.0(1.0)$ & $8.0(2.0)$ \\
Diallyl tetrasulphide & $0.5(0.125)$ & $2.0(0.5)$ \\
\hline
\end{tabular}

Data were expressed as mean (SD) $(n=5)$. therefore, these two oils could be considered as potent functional foods or potential therapeutic agents for clinical MRSA and fungal infections. Further study is necessary to examine the concentrations reached in the circulation and recovery in urine after these two agents are taken orally.

Lawson et al. [11] reported that the sum of diallyl monosulphide, disulphide, trisulphide and tetrasulphide in garlic oil was $54.5 \%$ of total sulphides. The present study used a similar method to quantify the four diallyl sulphides and found that the sum of these sulphides in garlic oil was $52.7 \%$, close to the figure of Lawson et al. [11]. The analysis of four diallyl sulphides was extended to Chinese leek oil and it was found that both oils contained high concentrations of three of these four diallyl sulphides. The concentration of diallyl monosulphide in these oils was quite low (c. $2.0 \%$ ) and the antimicrobial activity of this agent was not as marked (Tables 2 and Table 3). Thus the contribution of this agent to the overall antimicrobial activity of these oils appears small. The concentration of the other three diallyl sulphides (diallyl disulphide + diallyl trisulphide + diallyl tetrasulphide) in garlic oil was significantly higher than in Chinese leek oil. This may explain why garlic oil showed greater antimicrobial activity than Chinese leek oil.

$S$. aureus can produce a $\beta$-lactamase, and this enzyme inactivates penicillin by hydrolysing the $\beta$-lactam ring of the antibiotic $[22,23]$. In the present study, $\beta$ lactamase was produced by all clinical MRSA isolates. Furthermore, resistance to methicillin confers resistance to all penicillinase-resistant penicillins and cephalosporins; this resistance is due to the presence of the mec gene that encodes penicillin-binding proteins (PBPs) [24, 25]. So far, altered forms of PBPs such as PBP 1a and 2b have been implicated in the development of penicillin and cephalosporin resistance $[24,26]$. Based on MICs, the six test agents were less active against $40 \mathrm{~S}$. aureus isolates than four antibiotics; however, they showed greater inhibitory effects against MRSA than these antibiotics. Although the mechanism of action of these agents has not been investigated in gram-positive bacteria, it is unlikely that they are just affecting $\beta$-lactamase.

Table 3. MIC of garlic oil, Chinese leek oil and four diallyl sulphides against three Candida and three Aspergillus species

\begin{tabular}{|c|c|c|c|c|c|c|}
\hline \multirow{2}{*}{$\begin{array}{l}\text { Species (number } \\
\text { of isolates) }\end{array}$} & \multicolumn{6}{|c|}{ MIC $(\mathrm{mg} / \mathrm{L})$ of agent } \\
\hline & Garlic oil & Chinese leek oil & DAS & DADS & DAT & DATS \\
\hline C. albicans (39) & $16.0(2.0)$ & $24.0(2.0)$ & $32.0(4.0)$ & $4.0(1.0)$ & $1.0(0.25)$ & $0.5(0.125)$ \\
\hline C. krusei (27) & $24.0(4.0)$ & $48.0(8.0)$ & $72.0(8.0)$ & $12.0(2.0)$ & $8.0(1.0)$ & $4.0(0.5)$ \\
\hline C. glabrata (25) & $32.0(4.0)$ & $40.0(8.0)$ & $54.0(8.0)$ & $8.0(2.0)$ & $4.0(1.0)$ & $2.0(0.5)$ \\
\hline A. niger (31) & $20.0(2.0)$ & $32.0(4.0)$ & $40.0(4.0)$ & $8.0(2.0)$ & $2.0(0.5)$ & $1.0(0.25)$ \\
\hline A. flavus (26) & $40.0(8.0)$ & $64.0(8.0)$ & $64.0(8.0)$ & $12.0(4.0)$ & $4.0(2.0)$ & $2.0(1.0)$ \\
\hline A. fumigatus (28) & $32.0(4.0)$ & $56.0(8.0)$ & $54.0(4.0)$ & $12.0(2.0)$ & $8.0(2.0)$ & $4.0(2.0)$ \\
\hline
\end{tabular}

DAS, diallyl monosulphide; DADS, diallyl disulphide; DAT, diallyl trisulphide; DATS, diallyl tetrasulphide. Data were expressed as mean (SD) $(\mathrm{n}=5)$. 
Previously, the inhibitory effect of diallyl monosulphide and diallyl disulphide against Klebsiella pneumoniae, an opportunist pathogen causing nosocomial infection, was observed [27]. In this case, the effect was due to inhibition of arylamine $\mathrm{N}$-acetyltransferase activity in this organism with diallyl disulphide showing greater activity than diallyl monosulphide. In the study by Naganawa et al. [12], the anti-C. albicans activity of diallyl disulphide was also significantly greater than diallyl monosulphide. These authors indicated that the disulphide bond of diallyl disulphide was important for its antifungal activity. In the present study, both diallyl monosulphide and diallyl disulphide showed activity against MRSA and fungi, however, once again diallyl disulphide was more active than diallyl monosulphide. The antifungal effect of diallyl trisulphide against Cryptococcus neoformans has been described previously [28]. In the present study this compound as well as diallyl tetrasulphide was active against MRSA, Candida spp. and Aspergillus spp. (Tables 2 and Table 3 ), with the order of activity being diallyl tetrasulphide $>$ trisulphide $>$ disulphide. The number of disulphide bonds in the four diallyl sulphides is $0,1,2$ and 3 , respectively and it appears that the antimicrobial activity of these compounds is related to the number of bonds; the more disulphide bonds, the greater the antimicrobial activity.

The MICs of diallyl disulphide, diallyl trisulphide and diallyl tetrasulphide against MRSA, Candida spp. and Aspergillus spp. were all $\leqslant 12 \mathrm{mg} / \mathrm{L}$ and diallyl tetrasulphide was active at concentrations similar to conventional antibiotics. These agents occur naturally in foods such as garlic and Chinese leek and, therefore, the concentrations these agents achieve in vivo appear to be safe. However, further in- vivo study is necessary to evaluate the clinical application of these three agents for infections.

In conclusion, diallyl disulphide, diallyl trisulphide, diallyl tetrasulphide and essential oils rich in these three sulphides possess potent antimicrobial activities, suggesting that they may be useful in the prevention or treatment of a variety of infections.

\section{References}

1. Chen ML, Chang SC, Pan HJ et al. Longitudinal analysis of methicillin-resistant Staphylococcus aureus isolates at a teaching hospital in Taiwan. J Formos Med Assoc 1999; 98: 426-432.

2. Chang SC, Hsu LY, Luh KT, Hseih WC. Methicillin-resistant Staphylococcus aureus infections Taiwan I Hseuh Hui Tsa Chih 1988; 87: 157-163.

3. Hung CC, Chen YC, Chang SC, Luh KT, Hsieh WC. Nosocomial candidemia in a university hospital in Taiwan. J Formos Med Assoc 1996; 95: 19-28.

4. Yoshida S, Katsuzaki H, Ohta R et al. An organosulfur compound isolated from oil-macerated garlic extract, and its antimicrobial effect. Biosci Biotechnol Biochem 1999; 63: $588-590$.

5. Agarwal KC. Therapeutic actions of garlic constituents. Med Res Rev 1996; 16: 111-124.
6. Liu C-T, Chen H-W, Sheen L-Y, Kung Y-L, Chen PC-H, Lii CK. Analytical methods-effect of garlic oil on hepatic arachidonic acid content and immune response in rats. $J$ Agric Food Chem 1998; 46: 4642-4647.

7. Wargovich MJ. Diallyl sulfide, a flavor component of garlic (Allium satirum) inhibits dimethylhydrazine-induced colon cancer. Carcinogenesis 1987; 8: 487-489.

8. Haber-Mignard D, Suschetet M, Berges R, Astorg P, Siess MH. Inhibition of aflatoxin B1- and N-nitrosodiethylamine-induced liver preneoplastic foci in rats fed naturally occurring allyl sulfieds. Nutr Cancer 1996; 25: 61-70.

9. Dwivedi C, Abu-Ghazaleh A, Guenther J. Effects of diallyl sulfide and diallyl disulfide on cisplantin-induced changes in glutathione and glutathione-S-transferase activity. Anti-cancer Drugs 1996; 7: 792-794.

10. Haber D, Siess MH, Canivenc-Lavier MC, Le Bon AM, Suschetet M. Differential effects of dietary diallyl sulfide and diallyl disulfide on rat intestinal and hepatic drug-metabolizing enzymes. J Toxicol Environ Health 1995; 44: 423-434.

11. Lawson LD, Wang ZJ, Hughes BG. Identification and HPLC quantification of the sulfides and $\operatorname{dialk}(\mathrm{en}) \mathrm{yl}$ thiosulfinates in commercial garlic products. Planta Med 1991; 57: 363-370.

12. Naganawa $R$, Iwata $N$, Ishikawa $K$, Fukuda $H$, Fujino $T$, Suzuki A. Inhibition of microbial growth by ajoene, a sulfurcontaining compound derived from garlic. Appl Environ Microbiol 1996; 62: 4238-4242.

13. González-Fandos E, Garcia-López ML, Sierra ML, Otero A. Staphylococcal growth and enterotoxins (A-D) and thermonuclease synthesis in the presence of dehydrated garlic. $J$ Appl Bacteriol 1994; 77: 549-552.

14. Yin M-C, Cheng W-S. Food chemistry/biochemistry antioxidant activity of several Allium members. J Agric Food Chem 1998; 46: 4097-4101.

15. Yin MC, Tsao SM. Inhibitory effect of seven Allium plants upon three Aspergillus species. Int J Food Microbiol 1999; 49: 49-56.

16. Ravid U, Putievsky E. In: Svendsen B, Scheffer JJC (eds) Essential oils and aromatic plants. Dordrecht, The Netherlands, Martinus Nijhoff. 1985: 155-161.

17. Sparnins VL, Barany G, Wattenberg LW. Effects of organosulfur compounds from garlic and onions on benzo[a]pyreneinduced neoplasia and glutathione S-transferase activity in the mouse. Carcinogenesis 1988; 9: 131-134.

18. Warent NG, Hazen KC. Candida, Cryptococcus and other yeast of medical importance. In: Murray PR, Baron EJ, Pfaller MA, Tenover FC, Yolken RH (eds) Manual of clinical microbiology, 6th edn. Washington, DC, ASM 1995: Press. $723-737$.

19. National Committee for Clinical Laboratory Standards. Performance standards for antimicrobial susceptibility testing. Ninth informational supplement M 100-S9 Villanova, PA, National Committee for Clinical Laboratory Standards. 1999.

20. National Committee for Clinical Laboratory Standards Documents M27. Villanova, PA, National Committee for Clinical Laboratory Standards. 1995.

21. SAS User's Guide: Statistics. Cary, NC, SAS Institute. 1990.

22. Lowy FD. Staphylococcus aureus infections. N Engl J Med 1998; 339: 520-532.

23. Coffey TJ, Dowson CG, Daniels J, Spratt BG. Genetics and molecular biology of $\beta$-lactam-resistant pneumococci. Microb Drug Resist 1995; 1: 29-34.

24. Hiramatsu K, Hanaki H, Ino T, Yabuta K, Ogam T, Tenover FC. Methicillin-resistant Staphylococcus aureus clinical strain with reduced vanocmycin susceptibility. $J$ Antimicrob Chemother 1997; 40: 135-136.

25. Schaberg DR, Zervos MJ. Intergeneric and interspecies gene exchange in gram-positive cocci. Antimicrob Agents Chemother 1986; 30: 817-822.

26. Chambers HF. Methicillin resistance in staphylococci: molecular and biochemical basis and clinical implication. Clin Microbiol Rev 1997; 10: 781-791.

27. Chen G-W, Chung J-G, Ho H-C, Lin J-G. Effects of the garlic compounds diallyl sulphide and diallyl disulphide on arylamine $\mathrm{N}$-acetyltransferase activity in Klebisella pneumoniae. $\mathrm{J} \mathrm{Appl}$ Toxicol 1999; 19: 75-81.

28. Shen J, Davis LE, Wallace JM, Cai Y, Lawson LD. Enhanced diallyl trisulfide has in vitro synergy with amphotericin B against Cryptococcus neoformans. Planta Med 1996; 62: 415-418. 